Research Article

\title{
Bactericidal and Cytotoxic Properties of Silver Nanoparticle Synthesized from Root Extract of Asparagus Racemosus
}

\author{
Kalyani Khanra ${ }^{1}$, Sudipta Panja ${ }^{1}$, Indranil Choudhuri ${ }^{1}$, Anindita Chakraborty ${ }^{2}$ \\ Nandan Bhattacharyya ${ }^{1}$ \\ ${ }^{1}$ Department of Biotechnology, Panskura Banamali College; Panskura RS; PIN 721152; Purba Medinipur; West Bengal; India \\ ${ }^{2}$ Radiation Biology Division, UGC-DAE CSR, Kolkata Centre, Sector III, LB-8 Bidhan Nagar, Kolkata 700098; India \\ Corresponding author: E-mail: bhattacharyya_nandan@rediffmail.com
}

Received: Oct. 4, 2015; Accepted: Mar. 10, 2016; Published: Mar. 14, 2016.

Citation: Kalyani Khanra, Sudipta Panja, Indranil Choudhuri,Anindita Chakraborty and Nandan Bhattacharyya. Bactericidal and Cytotoxic Properties of Silver Nanoparticle Synthesized From Root Extract of Asparagus Racemosus. Nano Biomed. Eng. 2016 8(I), 39-46.

DOI: 10.5101/nbe.v8il.p39-46

\begin{abstract}
To evaluate the bactericidal, and cytotoxicity properties of silver nanoparticles synthesized from root extract of Asparagus racemosus. The physical properties of these nanoparticles were characterized by Transmission Electron Microscopy (TEM), Scanning Electron Microscopy (SEM), XRD and UVVis spectrophotometric analysis. The biochemical properties were assayed by antibacterial study, cytotoxicity assay using cancer cell line. The formation of silver nanoparticles was confirmed by UVVIS spectroscopic analysis which showed absorbance peak at $420 \mathrm{~nm}$. X-ray diffraction photograph indicated the face centered cubic structure of the synthesized AgNPs. TEM has displayed the different dimensional images of biogenic silver nanoparticles with particle size distribution ranging from 30$50 \mathrm{~nm}$. Silver particles are spherical in shape. The EDX analysis was used to identify the elemental composition of synthesized AgNPs. Antibacterial activity of the synthesized AgNPs against three Gram positive and Gram negative bacteria strains like Staphylococcus aureus, Escherichia coli and Pseudomonas aeruginosa carried out showed significant zones of inhibition. The cytotoxicity study by AgNPs also showed cytotoxicity on ovarian cancer cell line PA-1. The present study confirms that the AgNPs have great promise as antibacterial, and anticancer agent.
\end{abstract}

Keywords: Asparagus racemosus; Silver nitrate; Silver nanoparticles; Antibacterial activity; Cytotoxicity

\section{Introduction}

Nanotechnology is an interdisciplinary field of research interspersing material science, bionanoscience and technology. Remarkable advances are made in the field of biotechnology and nanotechnology to harness the benefit of life sciences, health care and industrial biotechnology [1-4]. There is constant interest in the synthesis of noble metal nanoparticles (NP) for their applications such as catalysis, electronics, optics, environment and biotechnology. Biosynthesis of NP is simple methods but its application is greater in human welfare. Metallic NPs are widely used for their antimicrobial functionality; for example, silver NPs (AgNPs) have been incorporated into wound dressings, bone cements and implants. In recent years, there has been growing interest in the manufacture of silver 
nanoparticles. Owing to their applicability in such wide sectors, their demand is increasing at an overwhelming rate. The increased demand has consequently resulted in increased production. Researchers are continuously developing methods for synthesis of highly mono-dispersed AgNPs which are efficient in terms of synthesis rate as well as application $[5,6]$. As nanoparticles are very minute in size, it can penetrate cells and cellular organelles and disrupt the normal function of cells. It is also associated with health risk as it less efficiently removed than larger particles by the macrophage clearances mechanisms in the lungs causing lungs damage and it can translocate through the circulatory system to organs and effect tissue damage by altered cellular redox balance toward oxidation, causing abnormal function or cell death and tissue inflammation. But synthesis of nano silver particle is economic and easy to prepared nanoparticle. Recently, plant extracts have been reported to show high efficacy in Au NPs synthesis such as Anacardium occidentale [7], Centella asiatica [8], Chenopodium album [9], Coleus amboinicus [10], Crocus sativus [11], Euphorbia hirta [12], Mangifera indica [13], Macrotyloma uniflorum [14], Trianthem adecandra [15], Murray akoenigii [16], Piper betlel [17], and seed extracts used for Terminalia chebula [18] and Cuminum cyminm [19]. Very few works had been done in the Au NPs synthesis using fruit extract such as Abelmoschus esculentus [20], Citrus limon, Citrus reticulata and Citrus sinensis [21]. However, our green synthesis method is very useful compared to the chemical method to minimizethe cost of value. This methodology offers huge advantages of cost effectiveness, biocompatibility for drug delivery application and large-scale production.

Biomolecules present in plant extracts can be used to reduce metal ions to form nanoparticles in a singlestep green synthesis process. This biogenic reduction of metal ion to base metal is quite rapid and can easily be scaled up. Synthesis of inorganic nanoparticles by biological systems makes nanoparticles more biocompatible and environmentally harmless. The reducing agents involved include the various water soluble plant metabolites (e.g. alkaloids, phenolic compounds, and terpenoids) and co-enzymes [22-25]. Silver $(\mathrm{Ag})$ and gold $(\mathrm{Au})$ nanoparticles have been the particular focus of plant-based syntheses. Extracts of a diverse range of plant species have been successfully used in making nanoparticles. The aim of research work is to make NP using plant extracts and determine its application in antimicrobial activity, and in cancer cell lines.

Satamuli is widely distributed in the tropical and sub-tropical region of India. The scientific name of the Satamuli medicinal plant is Asparagus racemosus Wild (Fig. 1). The spines of this medicinal plant are usually of $0.5 \mathrm{~cm}$ to $1.3 \mathrm{~cm}$ long. Rootstocks are short and tuberous which bear numerous numbers of $30 \mathrm{~cm}$ to $100 \mathrm{~cm}$ long succulent tuberous roots. In ayurveda, the plant parts play a major role for curing different diseases. In different regions, plant has different medicinal uses. Such as, in some parts of India the dried, powdered roots of this medicinal plant is being used for the treatment of leucorrhoea, sexual weakness and rheumatism, dyspepsia etc.in human beings. The roots of satamuli are considered alterative, stomachic, tonic, aphrodisiac and astringent to the bowels and
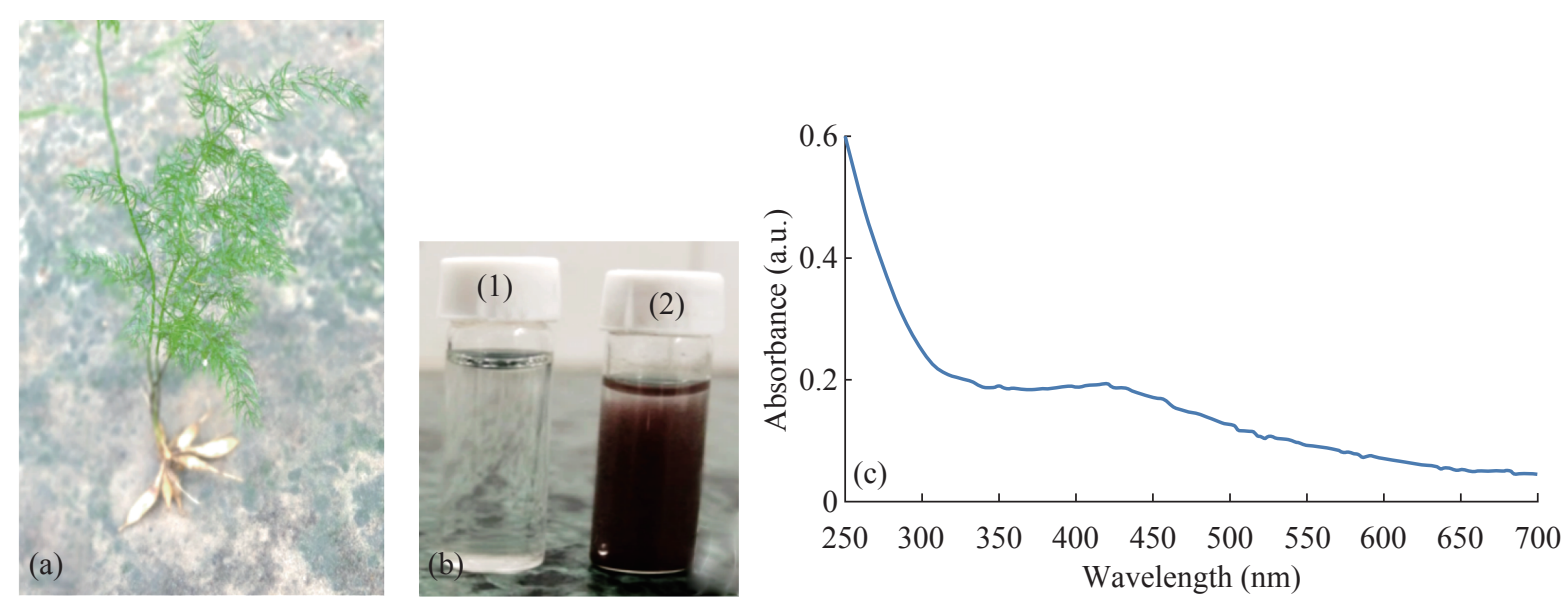

Fig. 1 (a) Asparagus racemosus whole plant with root. (b) Preparation of Nanoparticle from root extract of Asparagus racemosus. Figure shows extract before (1) and after (2) exposure to silver nitrate. (c) UV-Visible absorption spectra of biosynthesized silver Nanoparticle from Asparagus racemosus depicting peak at $421 \mathrm{~nm}$. 
roots are used in the treatment of kidney and liver disorders, gleet and gonorrhea, rheumatism and diseases of the nervous system [26-28]. We prepared nano-particle (NP) from roots of this plant and analyzed by biophysical and biochemicalassay.

\section{Materials and Methods}

\section{Preparation of root extract}

Roots of Shatamuli plant were collected from the different parts of Purba medinipur and Paschim medinipur, West. Bengal, India. They were washed thoroughly first with tap water to remove the soils and dirt, then with sterile double distilled water. The roots were air dried for a week at room temperature and finally the dried roots were grinded using mortar and pestle. Root powder was weighed $(10 \mathrm{~g})$ and mixed with $100 \mathrm{ml}$ of distilled water. The mixture was boiled in water bath for 10 minutes at $90^{\circ} \mathrm{C}$, after that it was filtered through Whatman No. 1 filter paper to obtain the pure root sample extract. The filtrate thus obtained was used as plant extract [29].

\section{Biosynthesis of nano-particle from $A$. racemosus}

Silver Nitrate solution $(1 \mathrm{mM})$ was freshly prepared by using $100 \mathrm{ml}$ distilled water. $10 \mathrm{ml}$ of plant extract was mixed with $190 \mathrm{ml}$ of $10^{-3}$ Msilver nitrate solution. The mixture was heated to $60{ }^{\circ} \mathrm{C}$ for $1 \mathrm{~h}$. Silver nano particle produced this way turn the solution light green to blackish in color.

\section{Characterization UV-Vis Spectroscopy}

The UV-Vis absorption spectra of the AgNPs were recorded using UV-Vis spectrophotometer UV-2450 (Shimadzu) at room temperature. The scanning range for the samples was $250-700 \mathrm{~nm}$ with a resolution of 1 $\mathrm{nm}$.

\section{Transmission Electron Microscopy (TEM)}

The morphology of the synthesized AgNPs was examined using TEM. Samples for TEM analysis were prepared by drop coating the Ag NPs solutions on carbon-coated copper grids at room temperature. The excess Ag NPs solution was removed with filter paper. The copper grid was finally dried at room temperature and was subjected to TEM analysis by the instrument JEM-1200EX electron microscope (JEOL, Tokyo,
Japan) instrument by operating at an accelerating voltage of $120 \mathrm{kV}$.

\section{X-ray Diffraction Analysis}

Crystallinity, structure, and crystallite size of AgNPs were determined by XRD technique using a X'Pert Pro X-ray diffractometer (PAN analytical BV, The Netherlands) operated at a voltage of $40 \mathrm{kV}$ and a current of $30 \mathrm{~mA}$ with $\mathrm{Cu} \mathrm{K} \alpha$ radiation in a $\theta-2 \theta$ configuration.

\section{SEM analysis \& EDAX}

Nanoparticles of Satamuli were suspended in deionized water and used for SEM analysis by fabricating a drop of suspension into a clean electric stub and allowing water to completely evaporate. SEM observations were carried out on a ZEISS EVO 40 EP Electron microscope. The synthesized AgNPs were characterized with the help of scanning electron microscopy (model LEO 440i) equipped with X-ray energy dispersive spectrometer (EDAX).

\section{Antibacterial assay}

The antibacterial activity of the AgNPs of satamuli was examined on two gram negative (pathogenic) and one gram positive bacteria namely Escherichia coli (Gram negative), Pseudomonas aeruginosa (Gram negative) and Staphylococcus aureus (Gram positive). These three strains were grown overnight. The freshly grown culture was mixed with molten nutrient agar and poured into petridishes. For assay of antibacterial activity, LB agar plates were prepared from Luria Broth agar. The plates were left overnight at $37^{\circ} \mathrm{C}$ to check for any contamination [30]. A $100 \mu$ l of fresh bacterial culture $\left(10^{5} \mathrm{cfu} / \mathrm{ml}\right)$ of each of the microorganism was used to prepare bacterial lawns on the agar plates. Antimicrobial activity of the synthesized AgNPs was determined using a modified Kirby Bauer disc diffusion method [31]. Three plates were prepared corresponding to each of the three bacterial strains. Each plate contains $10 \mathrm{ml}$ of plant extract, $2.5 \mathrm{ml}$ of antibiotic, $2.5 \mathrm{ml}$ and $5 \mathrm{ml}$ of AgNPs. In order to determine the synergistic effect of AgNPs and the antibiotic, separate plates were prepared only for two pathogenic bacteria. Each plate contains increasing concentrations of AgNPs $(2.5 \mu 1,5 \mu 1,7.5 \mu 1$, and $10 \mathrm{ml})$ keeping the concentration of antibiotic fixed $(2.5 \mathrm{ml})$. The plates were kept in $37{ }^{\circ} \mathrm{C}$ for 24 hour. Bactericidal activity with respect to zone of inhibition was also carried 
out. Ciprofloxacin $(0.19 \mu \mathrm{g} / \mathrm{ml})$ was used as standard antibiotic for both the pathogenic microorganism [32-34]. The plates were then incubated at $37^{\circ} \mathrm{C}$ for overnight. The assay for antibacterial activity was carried on the basis of diameter of zone of inhibition (in $\mathrm{mm}$ ) which was measured for each extract at the end of incubation period. Minimum inhibitory concentration of the antibiotic as well synthesized nanoparticle was evaluated as mentioned by Clinical and Laboratory Standard Institute (formerly known as National Committee for Clinically Laboratory Standards) [35]. Each experiment was performed thrice.

\section{Evaluation of cytotoxic activity on PA-1}

Human ovarian cancer cell line (PA-1) was seeded in 96-well tissue culture plate. After $24 \mathrm{~h}$ of cell attachment in plate, different concentration of nanoparticle were added to culture medium and incubated for $24 \mathrm{~h}$ at $37^{\circ} \mathrm{C}$. Non-treated cells were used as control. Incubated cultured cells were then subjected to tetrazolium salt 3-[4,5-dimethylthiazol2-yl]-2,5-diphenyltetrazolium bromide (MTT) colorimetric assay $[33,34]$. The MTT is used to determine cell viability and cytotoxicity. MTT was added at a final concentration of $0.5 \mathrm{mg} / \mathrm{ml}$ and the cells were incubated at $37^{\circ} \mathrm{C}$ for $3.5 \mathrm{~h}$. Then formazon dissolved with $100 \mathrm{ml}$ of DMSO in each well. The color changes were measured using a ELISA reader (Robonik, Readwell touch ELISA PLATE analyzer, India). The rate of survival was determined by using the following formulae: Cell viability $(\%)=(1-\mathrm{ODA} 1 /$ OD $\left.A_{o}\right) / 100$, where $A_{o}=$ Absorbency of control cells and $\mathrm{A}_{1}=$ Absorbency of treated cells $[36,37]$.

\section{Statistical analysis}

All the experiments were carried out in triplicate and the results were expressed as the mean. The results were expressed as mean $\pm \mathrm{SD}$. Statistical significances of difference throughout this study were calculated using a Student $t$ test and by one-way variance analysis.

\section{Results and discussion UV/VIS spectra analysis}

Aqueous extract of the Asparagus racemosusroot was mixed with the aqueous solution of the silver nitrate and boiled to reduce silver ions. Reaction exhibited change of color plant extract from watery to yellowish brown (Fig. 1(b)1 \& 1(b)2). It is due to reduction of silver ion of silver nitrate $(1 \mathrm{mM})$ which indicated formation of silver nanoparticles. It is generally recognized that UV-Vis spectroscopy could be used to examine size and shape of the nanoparticles in aqueous suspensions. Fig. 1(c) shows Absorption spectra of Ag-NPs formed in the reaction media had absorbance peak at $420 \mathrm{~nm}$, broadening of peak indicated that the particles are polydispersed.

\section{Transmission Electron Microscopy (TEM)}

Transmission electron microscopy was used to investigate the size, shape, and morphology of the silver nanoparticles synthesized. It is clear from high resolution TEM image (Fig. 2) that the as prepared Ag nanoparticles possess spherical shape. Histogram of the particle size distribution of AgNPs shows the average range of particle size is $30-50 \mathrm{~nm}$.

\section{XRD studies}

The biosynthesized silver nanostructure by using A.racemosus extract was further demonstrated and confirmed the crystalline nature of particles (Fig. 3). The characteristic peaks observed in the XRD image at $2 \theta=37.7,46.3,64,76.8$ corresponds to (111), (200), (220), and (311) set of lattice planes. The Bragg reflections observed in the XRD pattern corresponding to these sets of lattice planes were observed which may be indexed as face-centered crystal structure of silver. The unassigned peaks could be due to the crystallization of bioorganic phase that occurs on the surface of the nanoparticles.

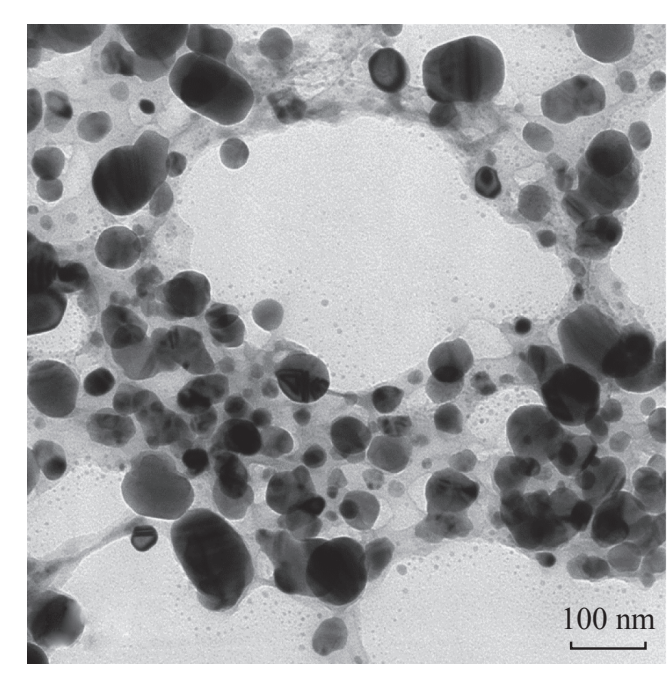

Fig. 2 TEM image of synthesized Ag-NP. 


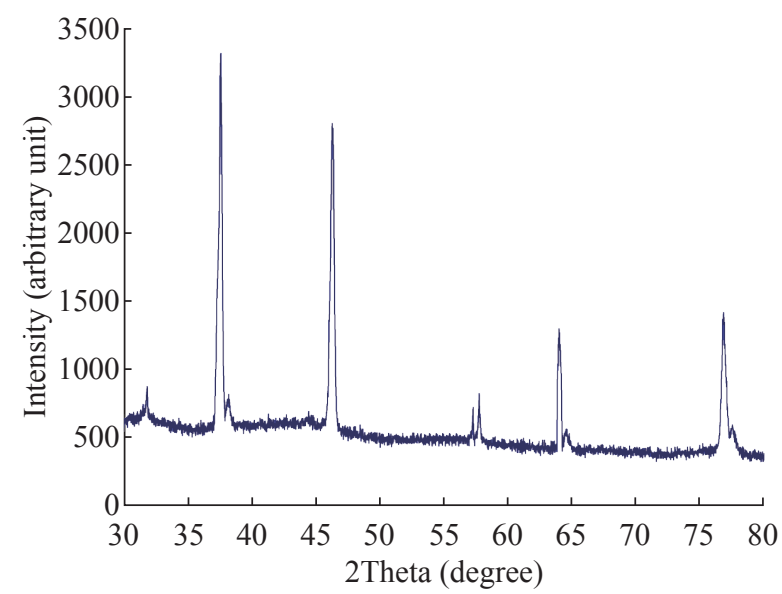

Fig. 3 XRD of Silver Nanoparticle Synthesis from Asparagus racemosus.

From the full width at half maximum, the grain size for the sample can be calculated from half widths of the major diffraction peak (111) according to Scherrer formula, $\mathrm{d}=\mathrm{K} \lambda / \mathrm{B} \cos \theta$, where $\mathrm{d}$ is the grain size, $\mathrm{K}=$ 0.89 is the Scherrer constant related to the shape and index (hkl) of the crystals, $\lambda$ is the wavelength of the $\mathrm{X}$-ray $(\mathrm{Cu} \mathrm{Ka}, 0.154056 \mathrm{~nm}), \theta$ is the diffraction angle, and $\mathrm{B}$ is the corrected full width at half maximum (in radian). The average crystallite size was found to be around $30-50 \mathrm{~nm}$, which is well consistent with the average particle diameter obtained from TEM images of Fig. 2.

Scanning electron microscopy shows high-density Ag nanoparticles synthesized by Satamuli plant extracts and further confirmed the presence of Ag nanoparticles. It was shown that relatively spherical in shape and is polydispersed without conglomeration in solution. The size of the AgNPs was found to be in the range of 30-50 nm (Fig. 4(a)). In EDAX strong signals of Ag were obtained in AgNPs and weaker signals for silica and oxygen were obtained (Fig. 4(b)).

The values of interplaner spacings $d$ hkl were calculated by using electron diffraction formula $R d \mathrm{hkl}$ $=\lambda L$ and the $\mathrm{X}$-ray diffraction $\lambda=2 d \mathrm{hkl} \cos \theta$, from the diameters of the diffraction rings and from the results of the XRD analysis. Regarding the FCC structure, $d \mathrm{hkl}=a / \sqrt{ } h 2+k 2+l 2$, the lattice parameter (1) was calculated by using the measured values of the spacing of the (111) plane. Table 1 presents the results of the lattice parameter and the spacing of the interplane measured in the XRD and TEM-SAED analyses These values were compared to standard ASTM data $(a=$ $0.409 \mathrm{~nm}$ ), the lattice constriction was found.

\section{Antibacterial study}

The in vitro antibacterial activity of Ag-NPs was studied against three bacteria (Fig. 5). The minimum inhibition concentrations (MIC) of ciprofloxacin for gram positive $S$. aureusis $150 \mathrm{mg} / \mathrm{ml}$; for gram negative E.coli is $100 \mathrm{mg} / \mathrm{ml}$; and for $P$. aeruginosa is $200 \mathrm{mg} / \mathrm{ml}$. For the biologically synthesized nanoparticles minimum inhibition concentration is noted to be $80 \mu \mathrm{g} / \mathrm{ml}$ for $S$. aureus, $30 \mathrm{mg} / \mathrm{ml}$ for E.coli, and $70 \mathrm{mg} / \mathrm{ml}$ for $P$. aeruginosa. It is also showed that the decrease in MIC value in case of combinations

Table 1 Comparison of spacings of the interplane $(d \mathrm{hkl})$ and the lattice parameter (1) with standard ASTM data

\begin{tabular}{cccc}
\hline Method & TEM $(\mathrm{nm})$ & XRD $(\mathrm{nm})$ & ASTM Standard value $(\mathrm{nm})$ \\
\hline Interplaner spacing (dhkl) & 0.297 & 0.297 & 0.298 \\
Lattice parameter (a) & 0.408 & 0.408 & 0.409 \\
\hline
\end{tabular}
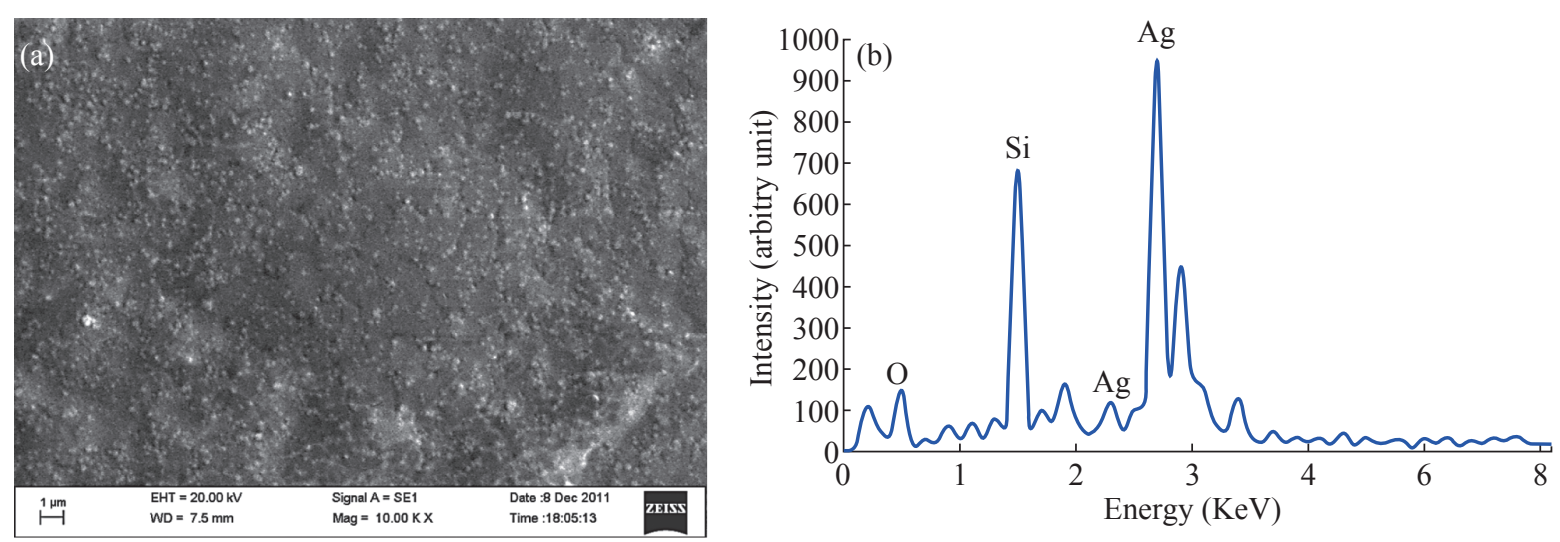

Fig. 4 SEM (a) \& EDAX (b) image and its table shows the dominant constituent of Ag in synthesized AgNPS. 

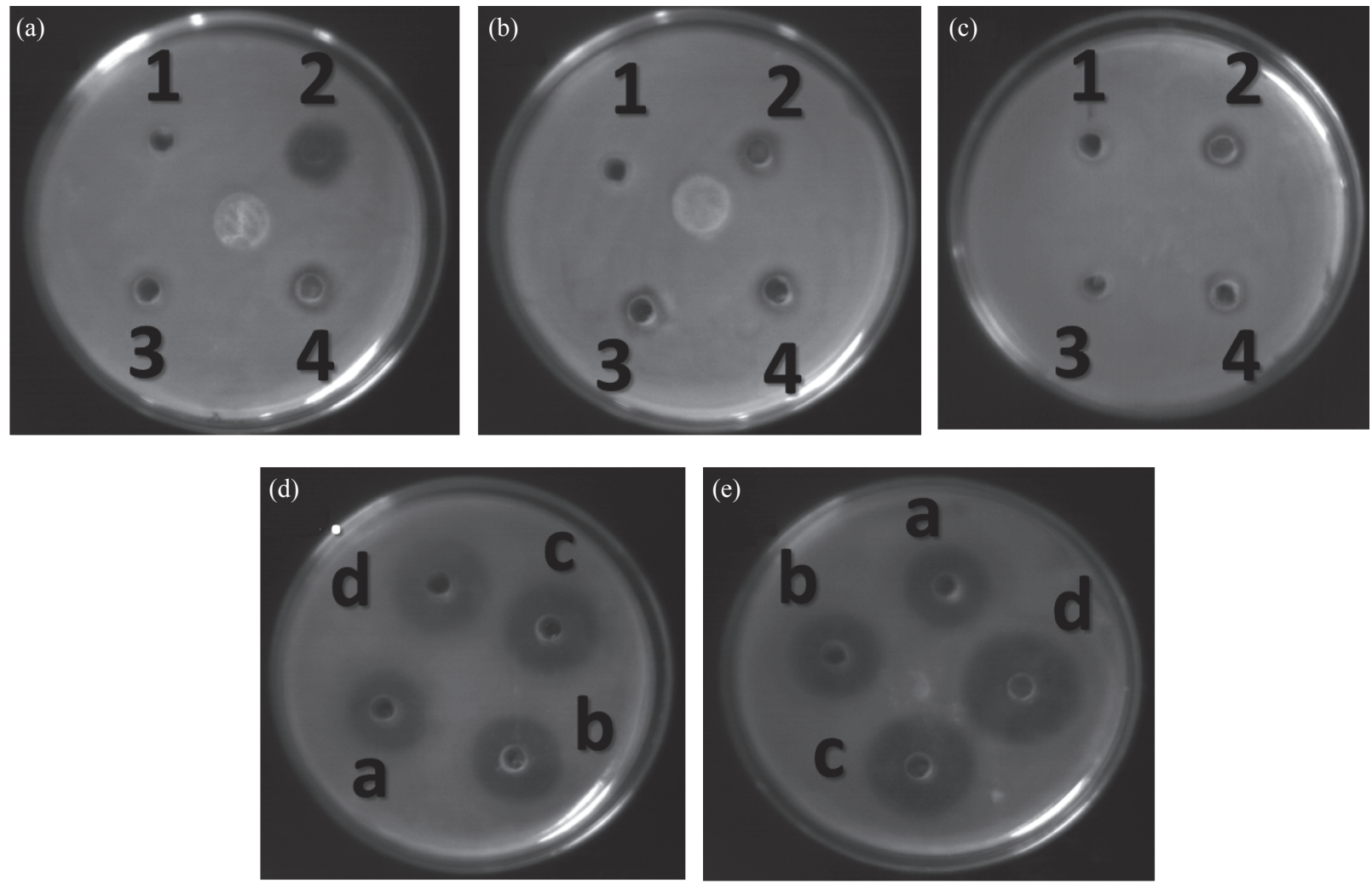

Fig. 5 Antibacterial activity of gram positive and gram negative bacteria. (a) Petridish containing Staphylococcus aureus, (b) Petridish containing Pseudomonas aeruginosa, (c) Petridish containing E. coli, (d) \& (e) Petridishes containing S. aureus. In petridishes (a), (b), and (c) well number -1, 2, 3, 4 denotes $10 \mu 1$ Plant extract, $2.5 \mu 1$ antibiotic, $2.5 \mu 1$ of AgNP and $5 \mu 1$ AgNP respectively. (d) and (e) represent the synergistic effect of AgNP and antibiotic. (a), (b), (c), (d) represent the result of effect of increasing concentrations of AgNPs $(2.5 \mu 1,5 \mu 1,7.5 \mu 1,10 \mu 1)$ mixed with $2.5 \mu 1$ of antibiotic.

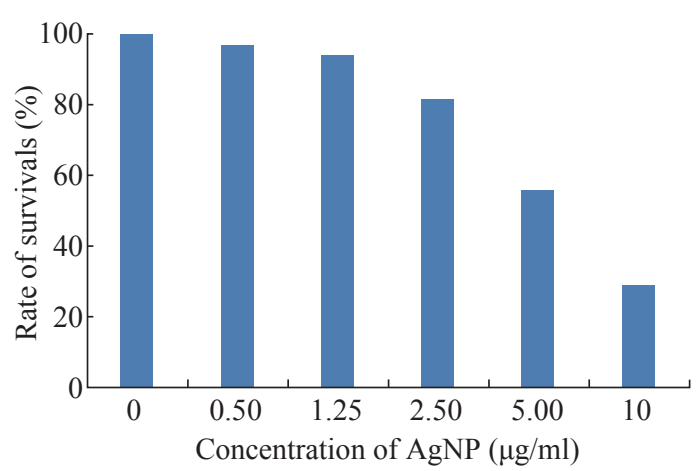

(a)

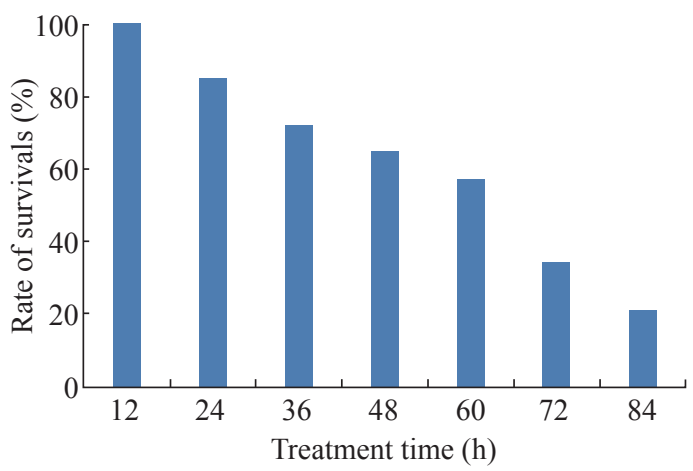

(b)

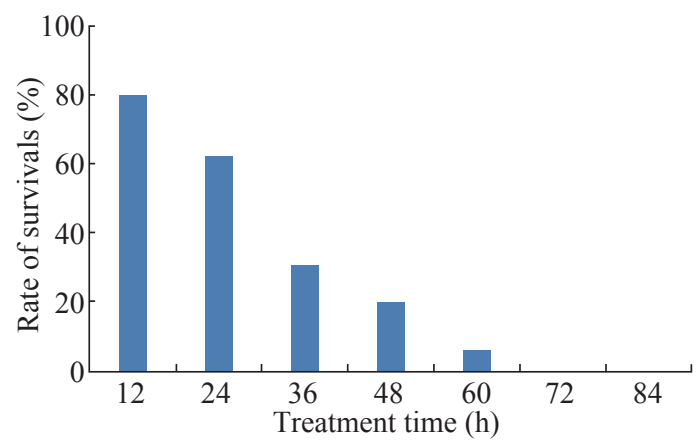

(c)

Fig. 6 (a) Rate of survival of PA-1 cells treated with various concentrations of silver nanoparticles for $24 \mathrm{~h}$. (b) Rate of survival of PA-1 cells treated with $0.5 \mu \mathrm{g} / \mathrm{ml}$ silver nanoparticles for various time. (c) Rate of survival of PA-1 cells treated with $5.0 \mu \mathrm{g} / \mathrm{ml} \mathrm{silver}$ nanoparticles for various time. 
of standard antibiotic ciprofloxacin and nanoparticle. As for example, in case of E.coli, combination of antibiotic and nanoparticles, MIC value of $200 \mathrm{mg} /$ $\mathrm{ml}$ was noticed; whereas, in case $S$. aureus, the same combination reduces the MIC value to $100 \mathrm{mg} / \mathrm{ml}$. Recently, it has been shown by some researchers that an inverse correlation between the size dependent bacteriocidal or bacteriostatic effect of nanoparticles $[38,39]$. They have shown that the less the size the more bacteriocidal or bacteriostatic effect. The MIC of S. aureus is shown to be in the range between $100 \&$ $130 \mathrm{mg} / \mathrm{ml}$ for Ag30 and Ag50 respectively. The MIC of E.coli is shown to be in the range between $100 \&$ $120 \mathrm{mg} / \mathrm{ml}$ for $\mathrm{Ag} 30$ and Ag50 respectively. The MIC of $P$. aeruginosum is shown to be in the range between $100 \& 130 \mathrm{mg} / \mathrm{ml}$ for $\mathrm{Ag} 30$ and Ag50 respectively. On the basis of these research works our future plan is to study the effect of the size and shape of our synthesized AgNPs on antimicrobial activity.

\section{Cytotoxicity study}

Cytotoxicity effect of AgNPs was tested against an ovarian cancer cell line PA-1 by MTT assay. The viability of PA-1 cells was sharply decreased in a dose dependent manner as shown in Fig. 6(a) (0.5$10 \mu \mathrm{g} / \mathrm{ml})$. In addition, the toxicity was detected after $24 \mathrm{~h}$ of treatment. The shape of the cells was round. In addition, the MTT data depicts the increment of cytotoxicity with the increase of higher concentrations of AgNPs. Fig. 6(b) and 6(c) show that rate of survival of PA-1 cells treated with $0.5 \mu \mathrm{g} / \mathrm{ml}$ and $5.0 \mu \mathrm{g} / \mathrm{ml}$ silver nanoparticles respectively for various time.

\section{Conclusions}

Nanoparticle prepared from plant extract is gaining popularity as it is simple and low cost, environmental friendly alternative to widely known chemical and physical methods. A hydrothermal method has been used for the synthesis of silver nanoparticles using plant extract of $A$. racemosus as a reducing agent. The synthesized AgNPs exhibited anti-microbial and anticancer activities. The work suggests that silver nanoparticles may provide potential applications as anti-microbial activities against pathogenic bacteria. In addition, the cytoxic nature against ovarian cancer cell line may have a therapeutic implication in the future. Hence, it can be explored as a promising option to reduce the infective potential of the tested pathogenic bacteria.

\section{Conflict of interest}

The authors declare that they have no conflict of interest.

\section{References}

[1] J.L. Gardea-Torresdey, J.G. Parsons, E. Gomez, et al., Formation and Growth of Au Nanoparticles inside Live Alfalfa Plants. Nano Letter, 2002, 2: 397-401.

[2] J.E. Hutchison, Greener nanoscience: a proactive approach to advancing applications and reducing implications of nanotechnology. ACS Nano, 2008, 2: 395402.

[3] Y. Zhang, D. Yang, Y. Kong, et al., Synergetic Antibacterial Effects of Silver Nanoparticles@ Aloe Vera Prepared via a Green Method. Nano Biomed. Eng., 2013, 5: 148-152.

[4] S. Soman, J. Ray, Phytosynthesis and Characterization of Silver Nanoparticles Using Leaf Extracts of Premna serratiffolia L. Nano Biomed. Eng., 2010, 2: 252-257.

[5] N.A. Begum, S. Mondal, S. Basu, et al., "Biogenic synthesis of $\mathrm{Au}$ and $\mathrm{Ag}$ nanoparticles using aqueous solutions of Black Tea leaf extracts". Colloids Surf B: Biointerfaces, 2009, 71: 113-118.

[6] B. Knoll, F. Keilmann, Near-field probing of vibrational absorption for chemical microscopy. Nature, 1999, 399: 134-138.

[7] D.S. Sheny, J. Mathew, D. Philip, Phytosynthesis of Au, Ag and Au-Ag bimetallic nanoparticles using aqueous extract and dried leaf of Anacardium occidentale. Spectrochim Acta A, 2011, 79: 254-262.

[8] R.K. Das, B.B. Borthakur, U. Bora, Green synthesis of gold nanoparticles using ethanolic leaf extract of Centella asiatica. Mater Lett., 2010, 64: 1445-1447.

[9] A.D. Dwivedi, K. Gopal, Biosynthesis of silver and gold nanoparticles using Chenopodium album leaf extract. Colloid Surface A, 2010, 369: 27-33.

[10] K.B. Narayanan, N. Sakthivel, Phytosynthesis of gold nanoparticles using leaf extract of Coleus amboinicus Lour. Mater Charact, 2010, 61: 1232-1238.

[11] R. Vijayakumar, V. Devi, K. Adavallan, et al., Green synthesis and characterization of gold nanoparticles using extract of anti-tumor potent Crocus sativus. Physica E., 2011, 44: 665-671.

[12] A. Annamalai, V.L. Christina, D. Sudha, Green synthesis, characterization and antimicrobial activity of Au NPs using Euphorbia hirta L. leaf extract. Colloid Surface B, 2013, 108: 60-65.

[13] D. Philip, Rapid green synthesis of spherical gold nanoparticles using Mangifera indica leaf. Spectrochimica Acta Part A: Molecular and Biomolecular Spectroscopy, 2010, 77: 807-810.

[14] S.A. Aromal, V.K. Vidhu, D. Philip, Green synthesis of well dispersed gold nanoparticles using Macrotyloma uniflorum. Spectrochim Acta Part A., 2012, 85: 99-104.

[15] R. Geethalakshmi, D.V. L. Sarada, Characterization and antimicrobial activity of gold and silver nanoparticles synthesized usingsaponin isolated from Trianthema decandra L. Ind Crop Prod., 2013, 51: 107-115.

[16] D. Philip, C. Unni, S. A. Aromal, et al., Murraya koenigii leaf-assisted rapid green synthesis of silver and gold nanoparticles. Spectrochim Acta Part A, 2011, 78: 899904. 
[17] K. Sneha, M. Sathishkumar, S. Kim, et al., Counter ions and temperature incorporated tailoring of biogenic gold nanoparticles. Process Biochem., 2010, 45: 1450-1458.

[18] K.M. Kumar, B.K. Mandal, M. Sinha, et al., Terminalia chebula mediated green and rapid synthesis of gold nanoparticles. Spectrochim Acta Part A, 2012, 86: 490494.

[19] K Sneha, M. Sathishkumar, S.Y. Lee, et al., Biosynthesis of Au nanoparticles using cumin seed powder extract. $J$ Nanosci Nanotechnol., 2011, 11: 1811-1814.

[20] C. Jayaseelan, R. Ramkumar, A.A. Rahuman, et al., Green synthesis of gold nanoparticles using seed aqueous extract of Abelmoschus esculentus and its antifungal activity. Ind. Crop Prod., 2013, 45: 423-429.

[21] M.V. Sujitha, S. Kannan, Green synthesis of gold nanoparticles using Citrus fruits (Citrus limon, Citrus reticulataand, Citrus sinensis) aqueous extract and its characterization. Spectrochim Acta Part A., 2013, 102: 15-23.

[22] M. Singh, S. Singh, S. Prasad, et al., Nanotechnology in medicine and antibacterial effect of silver nanoparticles. Digest Journal of Nanomaterials and Biostructures, 2008, 3: $115-122$

[23] A. Das, G. Shanker, C. Nath, et al., A comparative study in rodents of standardized extracts of Bacopa monniera and Ginkgo biloba: anticholinesterase and cognitive enhancing activities. Pharmacol Biochem Behav, 2002, 73: 893-900.

[24] R.J.P. Cannell, Natural Products Isolation, New Jersey: Human Press Inc, 1998: 4: 165-208.

[25] G. Saxena, S. Farmer, G.H.N. Towers, et al., Use of specific dyes in the detection of antimicrobial compounds from crude plant extracts using a thin layer chromatography agar overlay technique. Phytochemical analysis, 1995, 6(3): 125-129.

[26] D. Bown, D. Kindersley, Encyclopedia of Herbs \& Their Uses. ISBN: 0-7894-0184-3

[27] R.K. Goyal, J. Singh, H. Lal, Asparagus racemosus - an update. Indian J Med Science, 2003, 57: 408-414.

[28] N. Bopana, S. Saxena, Asparagus racemosusEthnopharmacological evaluation and conservation needs. J Ethnopharmacol, 2007, 110: 1-15.

[29] J.R. Morones, J.L. Elechiguerra, A. Camacho, et al., The bactericidal effect of silver nanoparticles. Nanotechnology, 2005, 16: 2346-2353.

[30] P.P. Durgawale, R.S. Phatak, A.S. Hendre, Biosynthesis of Silver Nanoparticle using latex of Syandenium grantiihook
$\mathrm{F}$ and its assessment of antibacterial activities. Digest Journal of Nanomaterials and Biostructures, 2015, 10: 847-853.

[31] A.W. Bauer, V.M. Kirby, J.C. Sherris, et al., Antibiotic susceptibility testing by a standardized single disk method. Am J Clin Pathol., 1966, 45 : 493-496.

[32] L.R. Beuchat, Pathogenic microorganisms associated with fresh produce. J Food Prot., 1996, 59: 204-216.

[33] B. Ahmad, I. Khan, S. Bashir, et al., Chemical composition and antifungal, phytotoxic, brine shrimp cytotoxicity, insecticidal and antibacterial activities of the essential oils of Acacia modesta. J. Med. Plants Res, 2012, 6: 4653-4659.

[34] R. Franklin, Methods for dilution antimicrobial susceptibility tests for bacteria that grow aerobically. Pennsylvania: NCCLS 32 2, 2012, M7-A9.

[35] A. Roy, K. Khanra, A. Mishra, et al., Highly cytotoxic (PA-1), less cytotoxic (A549) and antimicrobial activity of a green synthesized silver nanoparticle using Mikania cordata L. International Journal of Advanced Research, 2013, 1: 193-198.

[36] K. Khanra, A. Roy, N. Bhattacharyya, Evaluation of Antibacterial Activity and Cytotoxicity of Green Synthesized Silver Nanoparticles Using Hemidesmus indicus R. Br American J Nanoscience \& Nanotechnology Research, 2013, 1: 1-6.

[37] K. Khanra, S. Panja, I. Choudhuri, et al., Evaluation of Antibacterial Activity and Cytotoxicity of Green Synthesized Silver Nanoparticles Using Scoparia dulcis. Nano Biomed Eng., 2015, 7: 128-133.

[38] S. Agnihotri, S. Mukherji, S. Mukherji, Size controlled silver nanoparticles synthesized over the range 5-100 nm using the same protocol and their antibacterial efficacy. RSC Advances, 2014, 4: 3974-3983.

[39] K. Singh, M, Panghal, S, Kadyan, U, Chaudhary, JP, Yadav, Antibacterial activity of synthesized silver nanoparticles from Tinospora cordifolia against Multidrug resistant strains of Pseudomonas aeruginosa isolated from burn patients. J. Nanomed Nanotechnol., 2014, 5: 2-6.

Copyright $\subset 2016$ Kalyani Khanra, Sudipta Panja, Indranil Choudhuri, Anindita Chakraborty and Nandan Bhattacharyya. This is an open-access article distributed under the terms of the Creative Commons Attribution License, which permits unrestricted use, distribution, and reproduction in any medium, provided the original author and source are credited. 